\title{
ACADEMIC SUPERVISION IN IMPROVING TEACHERS' SKILLS DURING THE LEARNING PROCESS AT ELEMENTARY SCHOOL
}

\author{
Endriani $^{1}$, Fefi Yulita ${ }^{2}$ \\ ${ }^{1}$ SDN 11 Air Camar, Padang, Indonesia \\ ${ }^{2}$ SDN 29 Ganting Utara, Padang, Indonesia \\ 1endriani616@gmail.com,2yulifefi9@gmail.com
}

\begin{abstract}
The principal has an obligation to be able to improve the quality of teacher in the learning process at school. Based on the observations, it was found that the number of learning processes carried out by elementary school teachers at schools were not in accordance with the characteristics of elementary school students, so that improvements were needed to improve the skills of these teachers. The purpose of this study was to determine the improvement of teachers' skills in the learning process at elementary schools through academic supervision activities. This research was a classroom action research that adapted the design of Mc Taggart and Kemmist's classroom action research. This research consisted of stages of planning, implementation, observation and reflection. The findings stated that there was an increase in the implementation skills of the teacher's learning process by getting an average score of 68.46 in cycle 1 and increased to 86.10 in cycle 2. This proved that there was an increase in teachers' skills in the learning process at elementary schools through academic supervision activities. The implications of this research was that it could be used as a basis by supervisors to be able to improve teachers' skills in the learning process at elementary schools.
\end{abstract}

Keywords: academic supervision, teacher skills, learning, elementary school

\section{SUPERVISI AKADEMIK DALAM MENINGKATKAN KETERAMPILAN GURU DALAM PROSES PEMBELAJARAN DI SEKOLAH DASAR}

\begin{abstract}
ABSTRAK
Kepala sekolah memiliki kewajiban untuk dapat meningkatkan kualitas pebelajaran guru pada proses pembelajaran disekolah. Berdasarkan pengaatan diteumukan bahwa banyaknya proses pembelajaran yang dilaksanakan oleh guru sekolah dasar di sekolah yang peneliti pimpin tidak sesuai dengan karakteristik siswa sekolah dasar sehingga perlunya perbaikan untuk meningkatkan keterampilan guru tersebut. Tujuan penelitian ini adalah untuk mengetahui peningkatan keterampilan guru dalam proses pembelajaran di sekolah dasar melalui kegiatan supervisi akademik. Penelitian ini merupakan penelitian Tindakan kelas yang menyadur desain penelitian Tindakan kelas Mc Taggart dan Kemmist. Penelitian ini terdiri dari tahap perencanaan, pelaksanaan, pengamatan dan refleksi. Hasil temuan dinyatakan adanya peningkatkan keterampilan pelaksanaan proses pembelajaran guru dengan mendapatkan skor rata-rata pada siklus 1 sebesar 68,46 meningkat pada siklus 2 sebesar 86,10. Hal ini membuktikan bahwa adanya peningkatan keterampilan guru dalam proses pembelajaran di sekolah dasar melalui kegiatan supervisi akademik. Implikasi penelitian ini dapat dijadikan sebagai landasan oleh supervisor untuk dapat meningkatkan keterampilan guru dalam proses pembelajaran di sekolah dasar.
\end{abstract}

Kata Kunci: supervisi akademik, keterampilan guru, pembelajaran, sekolah dasar

\begin{tabular}{|c|c|c|}
\hline Submitted & Accepted & Published \\
\hline 13 Juni 2021 & 08 September 2021 & 17 September 2021 \\
\hline
\end{tabular}

\begin{tabular}{|l|l|l|l|}
\hline Citation & $:$ & $\begin{array}{r}\text { Endriani., \& Yulita, F. (2021). Academic Supervision in Improving Teachers' Skills during the Learning Process at } \\
\text { Elementary School. Jurnal PAJAR (Pendidikan dan Pengajaran), 5(5), 1475-1482. DOI : } \\
\text { http://dx.doi.org/10.33578/pjr.v5i5.8515. }\end{array}$ \\
\hline
\end{tabular}

\section{PENDAHULUAN}

Salah satu tugas seorang kepala sekolah adalah melakukan supervisi akademik dalam proses pembelajaran yang berada di sekolahnya (Kartini et al, 2020; Asniarny, 2020). Dalam melaksanakan supervisi, kepala sekolah harus mampu memahami hakikat supervisi akademik sebagai dasar keilmuan seorang kepala sekolah (Rahabav, 2016). Hal ini bertujuan agar tugas kepala sekolah sebagai supervisor dapat terlaksana yang bermuara kepada meningkatnya keprofesionalan guru. Dengan adanya kolaborasi antara kepala sekolah dan guru dalam supervisi 
akademik maka akan meningkatknya mutu dan kualitas pembelajaran di sekolah tersebut (Saihu, 2020). Selain itu dengan adanya kerjasama yang kolaboratif ini membuktikan adanya hubungan baik antara guru dan kepala sekolah dalam melaksanakan tugas masing-masing. Dalam melaksanakan proses supervisi akademik maka dibutuhkan keterampilan konseptual, keterampilan interpersonal dan keterampilan teknikal (Perason and Brew, 2002). Maka kepala sekolah harus mampu menguasai kemampuan tersebut agar terlaksananya proses supervisi yang dapat berdampak kepada peningkatan keterampilan guru. Supervisi akademik akan berpengaruh kepada proses pembelajaran yang dilaksanakan oleh guru (Mujiati et al, 2019). Guru akan mengubah mindset nya dalam proses pembelajaran (Ambarita et al, 2014). Hal ini akan terlihat ketika guru melaksanakan proses pembelajaran sehingga akan meningkatkan kualitas pembelajaran yang dilaksanakan. Oleh sebab itu supervisi akademik ini perlu dilaksanakan dalam proses pembelajaran. Termasuk pada proses pembelajaran di sekolah dasar.

Pada proses pembelajaran di sekolah dasar guru harus mampu mengembangkan proses pembelajaran yang sesuai dengan karakteristik siswa sekolah dasar (Kenedi et al, 2018). Siswa sekolah dasar merupakan siswa yang berada pada masa operasional kongkret (Kiswanto, 2017; Kenedi et al, 2019). Siswa yang berada pada masa operasional konkret adalah siswa yang belajar melalui benda-benda nyata maupun berdasarkan pengelaman nyata (Kenedi et al, 2019; Fitri et al, 2021). Selain itu pada masa ini siswa juga belajar untuk aktif menemukan sendiri informasi yang diinginkan (Kenedi et al, 2019; Miaz et al, 2019). Oleh sebab itu guru dalam proses pembelajaran di sekolah dasar harus mampu mendesaian pembelajaran yang mampu mengaktifkan siswa.

Tingkat keprofesionalan guru dapat dilihat dari proses pembelajaran yang dilaksanakan di sekolah (Postholm, 2012; Cansoy and Parlar, 2018). Guru yang professional akan mampu mengembangkan proses pembelajaran yang sesuai dengan karakteristik siswa sekolah dasar (Rahayu and Firmansyah, 2019). maka di sini lah tugas kepala sekolah sebagai supervisor. Kepala sekolah harus dapat memastikan bahwa proses pembelajaran yang dilaksanakan oleh guru harus sesuai dengan karakteristik siswa sekolah dasar (Kumala et al, 2018). berdasarkan landasan inilah peneliti sebagai kepala sekolah melakukan pengamatan terhadap proses pelaksanaan pembelajaran di SDN 11 Air Camar Kota Padang. Berdasarkan observasi yang peneliti lakukan ditemukan fakta bahwa guru masih menggunakan RPP dari wali kelas sebelumnya tanpa dikembangkan sendiri. Terlihat juga beberapa RPP yang digunakan oleh guru adalah RPP yang didownload dari internet. Selain itu RPP tersebut tidak menggunakan model pembelajaran yang sesuai dengan karakteristik siswa sekolah dasar. Peneliti juga menemukan fakta pada saat guru melaksanakan proses pembelajaran yaitu guru hanya menggunakan motode ceramah dalam proses pembelajaran tanpa memberikan umpan balik kepada siswa. Hal ini berdampak kepada proses pembelajaran yang bersifat teacher center. Selain itu guru tidak memberikan evaluasi pada proses pembelajaran. Analisis peneliti terhadap temuan ini adalah tidak maksimalnya guru dalam melaksanakan proses pembelajaran yang meliputi proses perencanaan, pelaksanaan dan penilaian pembelajaran. Terlihat guru tidak menggunakan model pembelajaran yang tidak sesuai dengan karakteristik siswa sekolah dasar.

Untuk mengatasi permasalahan tersebut diperlukan sebuah upaya. Upaya yang dapat dilakukan adalah dengan membina guru melalui kegiatan supervisi akademik (Tasrif, 2019). Hal ini bertujuan untuk dapat meningkatkan kualitas pelaksanaan pembelajaran yang berada di sekolah peneliti pimpin. Berdasarkan kajian literatur yang peneliti lakukan solusi yang dapat dilakukan adalah melakukan supervisi akademik untuk meningkatkan kualitas pelaksanaan pembelajaran yang dilaksanakan oleh guru (Saleh et al, 2012; Saihu, 2020). Dalam hal ini peneliti memperbaiki pembelajaran yang dilaksanakan oleh guru dengan membina guru menerapkan proses pembelajaran kooperatif tipe co op co op. Model pembelajaran kooperatif tipe co op co op adalah model pembelajaran yang bersifat kolaboratif dengan memberikan kesempata kepada siswa untuk dapat 
berkerjasama dalam menemukan informasi yang diinginkan melalui kelompok kecil yang dibentuk (Wardana et al, 2018). Dengan model pembelajaran ini siswa akan aktif menemuka informasi pembelajaran melalui kegiatan bersama kelompok kecil nya (Utami and Veronica, 2021). Hal ini sesuai dengan penelitian yang menyatakan bahwa model pembelajaran kooperatif tipe co op co op ini sangat tepat untuk dilaksanakan di sekolah dasar dikarenakan dapat meningkatkan kualitas pembelajaran di sekolah dasar (Hanayani et al, 2020).

Penelitian ini didukung oleh penelitian sebelumnya yang dilakukan oleh Sitaasih (2020) yang menyatakan bahwa supervisi akademik yang dilaksanakan dapat meningkatkan proses pembelajaran di sekolah. Namun penelitian ini berbeda yaitu supervisi akademik yang dilakukan difokuskan kepada proses peningkatkan pelaksanaan pembelajaran menggunakan model kooperatif tipe co op co op yang meliputi proses perencanaan pembelajaran, pelaksanaan pembelajaran dan penilaian pembelajaran. Maka tujuan penelitian ini adalah untuk meningkatkan keterampilan guru dalam melaksanakan proses pembelajaran menggunakan model kooperatif tipe co op co op melalui kegiatan supervisi akademik. Penelitian ini penting dilaksanakan dikarenakan dengan meningkatkan kualitas pembelajaran guru akan berdampak kepada peningkatan kualitas pembelajaran di sekolah dasar

\section{METODE PENELITIAN}

Penelitian ini merupakan penelitian tindak sekolah yang disesuaikan dengan tahapan penelitian Tindakan kelas yang terdiri dari tahapan tahap perencanaan, pelaksanaan, pengamatan dan refleksi. Pada tahapan perencanaan peneliti menyusun jadwal, penyusun rencana kegiatan dan penyusun instrument penilaian. Pada tahapan pelaksanaan peneliti melakukan kegiatan inti supervisi akademik. Pada tahapan pengamatan dilakukan proses penilaian kepada guru dan pada tahapan refleksi dilakukan proses analisis untuk memperbaiki kesalahan yang terjadi.

Kegiatan penelitian ini dilaksanakan di SDN 11 Air Camar Kota Padang sebanyak 10 guru pada tahun 2020. Teknik pengumpulan data menggunakan lembar observasi pengukuran hasil proses pembelajaran yang meliputi kemampuan perencanaan, kemampuan pelaksanaan dan kemampuan penilaian. Teknik analisis data terdiri dari data kuantitatif. Data kuantitatif untuk menganalis hasil lembar observasi:

1. Menghitung nilai rata-rata pelaksanaan pembelajaran

Adapun rumus yang digunakan yaitu

$$
P=\frac{\text { Skor yang didapat }}{\text { Skor maksimal }} \times 100
$$

2. Menghitung ketuntasan klasikal

$$
X=\frac{\text { Jumlah guru yang mendapatkan nilai } \geq 75}{\text { Jumlah semua guru }} \times 100
$$

Adapun indikator keberhasilan PTS ini adalah keterampilan guru dalam melaksanakan proses pembelajaran mendapakan skor minimal 75 dengan ketuntasan belajar klasikal $75 \%$.

\section{HASIL DAN PEMBAHASAN}

Kegiatan penelitian di awali dengan tahapan perencanaan. Tahapan perencanaan merupakan tahapan untuk menyusun kegiatankegiatan yang dilaksankan. Adapun kegiatan yang dilaksanakan dalam proses perencanaan ini adalah menyusun jadwal kegiatan, menyusun strategi kegiatan supervisi akademik dan menyusun instrument penilaian yang bertujuan untuk mengukur indicator keberhasilan yang telah ditetapkan. Setelah menyusun perencanaan maka selanjutnya dilakukan kegiatan supervisi pada proses pelaksanaan.

Pada tahapan pelaksanaan guru bersama peneliti membuat kesepakatan untuk melaksanakan kegiatan supervisi akademik dengan tujuan untuk meningkatkan kualitas guru dalam melaksanakan proses pembelajaran. Pada tahapan ini guru dilakukan pembinaan mengenai pengembangan model kooperatif tipe co op co op. guru diberikan pemahaman mengenai konsep dan komponen dari kurikulum 2013 yang terdiri dari data sekolah, matapelajaran, dan kelas/semester, materi pokok, alokasi waktu, tujuan pembelajaran, KD dan indikator pencapaian kompetensi, materi pembelajaran, metode pembelajaran, media, alat dan sumber belajar, langkah-langkah kegiatan pembelajaran; dan penilaian hasil belajar. Pada kegiatan ini guru dibina untuk mengembangkan 
RPP dengan memperhatikan langkah model kooperatif tipe co op co op yang terdiri dari dikusi kelas yang berpusat kepada siswa, pembentukan kelompok / tim, pembagian topik kelompok, pembagian topik kecil, persiapan topik kecil, presentasi topik kecil, persiapan presentasi tim, presentasi tim dan evaluasi. Selain dilakukan pembinaan terhadap pengembangan RPP, guru juga dilakukan pembinaan terhadap pengembangan system penilaian. Guru dilatih untuk dapat mengembangkan penilaian yang meliputi aspek keterampilan, pengetahuan dan sikap berdasarkan model kooperatif tipe co op co $o p$.
Setelah dibina melakukan pengembangan maka selanjutnya dilakukan penilaian guru dalam melaksanakan pembelajaran model kooperatif tipe co op co op didalam kelas. Guru diminta untuk menerapkan pembelajaran menggunakan model kooperatif tipe co op co op didalam kelas masingmasing. Sembari guru melaksanakan proses pembelajaran juga dilakukan pengamatan untuk mengukur kemampuan guru. Adapun kemampuan yang dinilai adalah kemampuan mengembangkan RPP, kemampuan mengembangkan penilaian, dan kemampuan melaksanakan pembelajaran. Adapun rekapitulasi hasil pengamatan dapat dilihat pada tabel berikut:

Tabel 1. Rekapitulasi Penilaian Siklus 1

\begin{tabular}{ll}
\hline \multicolumn{1}{c}{ Aspek } & Skor Rata-Rata \\
\hline Perancangan RPP & 68.52 \\
Perancangan penilaian & 67.34 \\
Pelaksanaan Pembalajaran & 69.52 \\
Rata-rata & 68.46 \\
\hline
\end{tabular}

Berdasarkan tabel 1 ditemukan bahwa guru mendapatkan skor rata-rata 68.46. Hasil dari pengamatan ini kemudian dianalisis pada tahapan refleksi.

Tahapan refleksi merupakan tahapan menganalisis kegiatan yang telah dilakukan. Hasil pengamatan mendapatkan skor rata-rata yaitu 68.46. Hal ini menyatakan bahwa belum tercapainya indicator keberhasilan yang telah ditetapkan. Hal ini dikarenakan ada beberapa kegiatan yang belum optimal dilakukan. Pada pengembangan RPP guru masih belum maksimal mengembangkan materi pembelajaran, media pembelajaran dan langkah-langkah pembelajaran. Selain itu berdasarkan lembar observasi masih terdapat kelemahan guru dalam melaksanakan pembelajaran kooperatif tipe co op co op. guru masih mendominasi proses pembelajaran. Selain itu terlihat guru masih canggung dalam melaksanakan proses pembelajaran tersebut. Oleh sebab itu dikarenakan masih belum tercapainya indicator keberhasilan dan masih terdapat kekurangan maka penelitian dilanjutkan pada siklus ke 2.
Tahap perencanaan pada siklus kedua tidak jauh berbeda dengan siklus 1 yaitu menyusun jadwal kegiatan, menyusun strategi kegiatan supervisi akademik dan menyusun instrument penilaian yang bertujuan untuk mengukur indicator keberhasilan yang telah ditetapkan. Setelah menyusun perencanaan maka selanjutnya dilakukan kegiatan supervisi pada proses pelaksanaan.

Pada tahapan pelaksanaan peneliti kembali membina guru terhadap pembuatan RPP dan merancang penilaian hasil belajar. Pada kegiatan ini peneliti kembali menekankan mengenai langkah-langkah model kooperatif tipe co op co op. Setelah dilakukan pembinaan guru kemudian diminta untuk menerapkannya dalam proses pembelajaran. Selama proses pembelajaran dilaksanakan terlihat guru dan siswa aktif dalam proses pembelajaran. Sembari guru melaksanakan proses pembelajaran juga dilakukan pengamatan untuk mengukur kemampuan guru. Adapun rekapitulasi penilaian siklus 2 dapat dilihat pada table berikut: 
Tabel 2. Rekapitulasi Penilaian Siklus 2

\begin{tabular}{ll}
\hline \multicolumn{1}{c}{ Aspek } & Skor Rata-Rata \\
\hline Perancangan RPP & 86.27 \\
Perancangan penilaian & 88.92 \\
Pelaksanaan Pembalajaran & 83.12 \\
Rata-rata & 86.10 \\
\hline
\end{tabular}

Berdasarkan tabel 2 ditemukan bahwa guru mendapatkan skor rata-rata 86,10. Hasil dari pengamatan ini kemudian dianalisis pada tahapan refleksi. Pada tahapan refleksi hasil pengamatan tersebut dianalisa. Berdasarkan hasil analisa dinyatakan bahwa hasil pengamatan telah mencapai indicator keberhasilan dan semua aktivitas guru telah sesuai yang diharapkan. Oleh sebab itu maka disepakati penelitian di cukupkan pada siklus 2. Dari hasil penelitian ini terlihat peningkatkan keterampilan guru dalam melaksanakan proses pembelajaran dengan model kooperatif tipe co op co op. Adapun visualiasi peningkatan tersebut dapat terlihat pada gambar berikut:

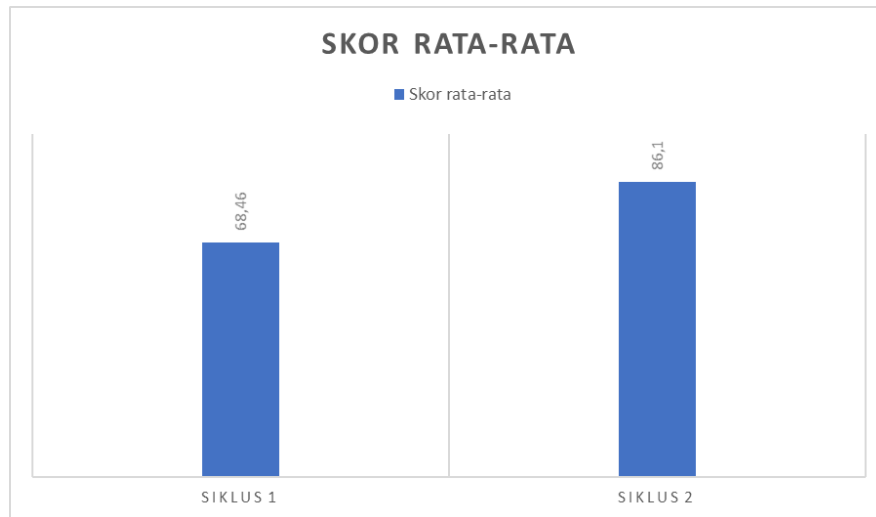

Gambar 1. Peningkatan Keterampilan Guru dalam Proses Pembelajaran

Dari gambar 1. terlihat adanya peningkatan keterampilan guru dalam proses pembelajaran di sekolah dasar. Hal ini membuktikan bahwa supervisi akademik dapat meningkatkan keterampilan guru dalam proses pembelajaran di sekolah dasar. hasil temuan ini selaras dengan temuan yang dilakuan oleh Bahri (2014) yang menyatakan bahwa supervisi akademik dapat meningkatkan kemampuan guru dalam membuat perencanaan pembelajaran. Penelitian tersebut selaras dengan penelitian ini yaitu sama-sama menggunakan supervisi akademik. Namun menjadi temuan yang berbeda dengan penelitian ini yaitu supervisi akademik yang dilakukan dapat meningkatkan keterampilan guru dalam melaksanakan proses pembelajaran yang meliputi perencanaan, pelaksanaan dan penilaian hasil belajar.
Supervisi akademik merupakan aktivitas yang bertujuan untuk melakukan pembinaan kepada guru yang memiliki permasalahan yang berhubungan dengan proses pembelajaran (Pratiwi et al, 2020). Supervisi akademik juga merupakan aktivitas yang bertujuan untuk meningkatkan kinerja guru dalam proses pengembangan pembelajaran (Pambudi and Gunawan, 2020). Fungsi dari proses supervisi akademik adalah untuk meningkatkan kualitas pembelajaran guru dan memastikan guru menjalankan tugas sebagai pendidik (Nurcholis et al, 2020). Oleh sebab itulah supervisi akademik dapat meningkatkan kualitas pembelajaran guru.

\section{SIMPULAN DAN REKOMENDASI}

Berdasarkan temuan dinyatakan adanya peningkatkan keterampilan pelaksanaan proses 
pembelajaran guru dengan mendapatkan skor ratarata pada siklus 1 sebesar 68.46 meningkat pada siklus 2 sebesar 86.10. Hal ini membuktikan bahwa adanya peningkatan keterampilan guru dalam proses pembelajaran disekolah dasar melalui kegiatan supervisi akademik. Implikasi penelitian ini dapat dijadikan sebagai landasan oleh supervisor untuk dapat meningkatkan keterampilan guru dalam proses pembelajaran disekolah dasar. Penelitian ini merekomendasikan agar perlunya kesepakatan jadwal supervisi akademik dengan guru agar proses supervisi dapat terlaksana dengan baik. Selain itu perlunya penelitian lanjutan untuk menemukan upaya dalam meningkatkan keterampilan guru sekolah dasar.

\section{DAFTAR PUSTAKA}

Ambarita, B., Siburian, P., \& Purba, S. (2014). Development of academic supervision model which based on educational management. International Journal of Sciences: Basic and Applied Research (IJSBAR), 18(1), 304-314.

Asniarny, A. (2019). Pelaksanaan Supervisi Akademik Pengawas Sekolah Dalam Meningkatkan Kinerja Guru Sekolah Dasar Di Kota Dumai. Jurnal Pajar (Pendidikan dan Pengajaran), 3(4), 764772.

Bahri, S. (2014). Supervisi akademik dalam peningkatan profesionalisme guru. Visipena, 5(1), 100-112.

Cansoy, R., \& Parlar, H. (2018). Examining the relationships between the level of schools for being professional learning communities and teacher professionalism. MOJES: Malaysian Online Journal of Educational Sciences, 5(3), 13-27.

Fitria, Y., Kenedi, A. K., \& Syukur, S. K. (2021). THE EFFECT OF SCIENTIFIC APPROACH ON ELEMENTARY SCHOOL STUDENTS'LEARNING OUTCOMES IN SCIENCE

LEARNING. JPsd (Jurnal Pendidikan Sekolah Dasar), 7(1), 78-90.

Handayani, Y., Lazim, N., Lazim, N., \& Noviana,
E. Penerapan Model Pembelajaran Kooperatif Tipe Co-op Co-op Untuk Meningkatkan Hasil Belajar IPS Siswa Kelas Vd SD Negeri 163 Pekanbaru (Doctoral dissertation, Riau University).

Kartini, D., Kristiawan, M., \& Fitria, H. (2020). The Influence of Principal's Leadership, Academic Supervision, and Professional Competence toward Teachers' Performance. International Journal of Progressive Sciences and Technologies, 20(1), 156-164.

Kenedi, A. K., Ahmad, S., Sofiyan, T. A. N., \& Helsa, Y. (2019). The Mathematical Connection Ability of Elementary School Students in the 4.0 Industrial Revolution Era. International Journal of Innovation, Creativity and Change, 5(5), 458-472.

Kenedi, A. K., Eliyasni, R., \& Fransyaigu, R. (2019, December). Jigsaw using animation media for elementary school. In Journal of Physics: Conference Series (Vol. 1424, No. 1, p. 012027). IOP Publishing.

Kenedi, A. K., Hendri, S., \& Ladiva, H. B. (2018). Kemampuan Koneksi Matematis Siswa Sekolah Dasar Dalam Memecahkan Masalah Matematika. Numeracy, 5(2), 226-235.

Kenedi, A. K., Sari, I. K., Ahmad, S., Ningsih, Y., \& Zainil, M. (2019, October). Mathematical connection ability of elementary school student in number materials. In Journal of Physics: Conference Series (Vol. 1321, No. 2, p. 022130). IOP Publishing.

Kiswanto, A. (2017, September). The effect of learning methods and the ability of students think logically to the learning outcomes on natural sciences of grade ivs student. In 9th International Conference for Science Educators and Teachers (ICSET 2017) (pp. 1040-1046). Atlantis Press.

Kumala, V. M., Susilo, J., \& Susanto, R. (2018). Hubungan Pengetahuan Pedagogik 
Dengan Kompetensi Pedagogik Serta Perbedaannya Di Sekolah Negeri Dan Sekolah Swasta. Hub. Pengetah. Pedagog. dengan akaompetensi Pedagog, 1-23.

Miaz, Y., Kenedi, A. K., Monafajri, W. S., \& Helsa, Y. (2019). Educative Learning Media For Elementary School Students. Advanced In Social Science, Education And Humanities Research, 382, 722-727.

Mujiati, M., Suriansyah, A., \& Effendi, R. (2019). Effect of Academic Supervision and School Culture on Teacher's Teaching Quality in Public Islamic Senior High School Banjarmasin. Journal of K6 Education and Management, 2(2), 126132.

Nurkolis, N., Warastuty, R., \& Yuliejantiningsih, Y. (2020, February). Do Academic Supervision and Activities in MGMP (Subject Teacher Deliberations) Increase Teachers Performance. In 3rd International Conference on Research of Educational Administration and Management (ICREAM 2019) (pp. 364371). Atlantis Press.

Pambudi, B. A., \& Gunawan, I. (2020, December). The Effect of Learning Leadership and Academic Supervision on Teacher Teaching Skills in the Covid-19 Pandemic. In 6th International Conference on Education and Technology (ICET 2020) (pp. 1-5). Atlantis Press.

Pearson, M., \& Brew, A. (2002). Research training and supervision development. Studies in Higher education, 27(2), 135-150.

Postholm, M. B. (2012). Teachers' professional development: a theoretical review. Educational research, 54(4), 405-429.

Pratiwi, F. D., Gunawan, I., Mahardika, B. A., Cahyaning, C. N., Amaliah, P. U., Adha, M. A., \& Lestari, S. P. (2020, December). Principal's Role in Thematic Learning Supervision That Works in Elementary School. In 6th International Conference on Education and Technology (ICET 2020) (pp. 176-181). Atlantis Press.

Rahabav, P. (2016). The Effectiveness of Academic Supervision for Teachers. Journal of Education and Practice, 7(9), 47-55.

Rahayu, G. D. S., \& Firmansyah, D. (2019). Pengembangan pembelajaran inovatif berbasis pendampingan bagi guru sekolah dasar. Abdimas Siliwangi, 1(1), $17-25$.

Saihu, S. (2020). The Urgency Of Total Quality Management In Academic Supervision To Improve The Competency of Teachers. Edukasi Islami: Jurnal Pendidikan Islam, 9(02), 297-323.

Saihu, S. (2020). The Urgency Of Total Quality Management In Academic Supervision To Improve The Competency of Teachers. Edukasi Islami: Jurnal Pendidikan Islam, 9(02), 297-323.

Saleh, S., Arismunandar, A., \& Anshari, A. (2021). The Contribution of Academic Supervision and Teacher Working Group on Teachers' Pedagogical Competence. Journal of Educational Science and Technology (EST), 7(1), 1825.

Sitaasih, D. K. (2020). Supervisi Akademik untuk Meningkatkan Kompetensi Guru Dalam Proses Pembelajaran di SD. Jurnal Ilmiah Sekolah Dasar, 4(2), 241-247.

Tasrif, E. (2019, February). Academic Supervision Mechanism by Vocational High School Supervisor. In 5th UPI International Conference on Technical and Vocational Education and Training (ICTVET 2018) (pp. 160-164). Atlantis Press.

Utami, I. W. P., \& Veronica, R. B. (2021). Students' mathematical communication skill in co-op co-op type of cooperative learning model reviewed by productive disposition. Unnes Journal of Mathematics Education, 10(1), 71-78.

Wardana, L. W., Setyani, R., \& Harwida, G. (2018). The implementation of the two stay two stray (tsts) learning model and co-op co-op for the improvement of 
Jurnal PAJAR (Pendidikan dan Pengajaran)

Volume 5 Nomor 5 September 2021 | ISSN Cetak : 2580 - 8435 | ISSN Online : 2614 - 1337

DOI : http://dx.doi.org/10.33578/pjr.v5i5.8515

students' learning outcome in the crafts and entrepreneurship subject. KnE Social

Sciences, 140-149. 